\title{
Study on Effects of Medroxyprogesterone Acetate on Serological Parameters, Ultrasonographic and Histopathological Profile of Uterine Endometrial Morphology in Female Rabbits
}

\author{
H.A. Tahir, U.F. Durrani, A.K. Mahmood, K. Matloob, M. Imran, R. Hussain
}

10.18805/IJAR.BF-1439

\begin{abstract}
Background: Rabbits are small mammals from the family Leporidae. Rapid multiplication profile of the rabbits often necessitates contraceptive controls in which ovario-hysterectomy is the only recommended method worldwide but still rabbit owners avoid surgical manipulation and opt for the contraceptive injections but contraceptive injections are also known to cause undesired effects in different animal species. The present study was conducted to evaluate effects of Medroxyprogesterone acetate on liver enzymes, lipid profile, blood glucose and uterine endometrial morphology.

Methods: The study was conducted on 20 breeding female rabbits at Pet Centre, University of Veterinary and Animal Sciences, Lahore, Pakistan. The study animals were divided into two groups, A and B having 10 rabbits each. Group A was treated with single dose of Medroxyprogesterone acetate $(10 \mathrm{mg} / \mathrm{kg} \mathrm{IM})$. While group B was kept as control and was given a single dose of $0.9 \%$ normal saline placebo injection. Pre and post treatment serum sampling was performed on days $0,7,14,21,28,35,42$ and histopathological evaluation of reproductive tract (mainly uterus) was conducted at the end of study.

Result: Serological parameters i.e. liver profile, lipid profile and blood glucose level (random) were significantly increased after treatment along with congestion, engorgement of blood vessels, degeneration, hyperplasia of uterine epithelium and uterine glands in Treatment group in contrast to control group. On the basis of this study it was concluded that Medroxyprogesterone acetate poses undesirable effect on the uterine endometrium and different serological parameters of body like liver enzymes (total bilirubin, alanine aminotransferase, aspartate aminotransferase, alkaline phosphatase), blood glucose, lipid profile (cholesterol, high density lipoprotein, low density lipoprotein, triglyceride).
\end{abstract}

Key words: Contraceptive, Doe, Medroxyprogesterone, Progesterone, Rabbit.

\section{INTRODUCTION}

The domestic rabbit (Oryctolagus cuniculus) is commercialized for several purposes such as experimentation and domestication (Fuentes, 2008) and is bred commercially for skin and meat because of high protein, vitamin and mineral contents with low fat as compared to beef and chicken meat (Jiménez-Colmenero, 2001). Rabbits' population growth is very fast because of their efficient reproductive rate which often necessitates intervention. Surgical sterilization i.e. ovario-hysterectomy and orchiectomy are the internationally recommended and permanent methods of population control for pet animals. The alternative to surgical sterilization techniques is medicinal contraception which involves use of contraceptive drugs to prevent estrus (Kutzler, 2006). Contraceptive drugs prevent ovulation by acting on the adenohypophysis which in turn prevents release of gonadotropins, $\mathrm{GnRH}$ (Srivastava, 2004). Although there are many contraceptive choices which can be used in rabbits (Risi, 2014) empirically derived from human literature, the commonly used human contraceptives are steroid hormones, which are $\mathrm{GnRH}$ analogues (Deslorelin acetate) androgens (mibolerone) and prostaglandins (dinoprost tromethamine). The combination of synthetic progestin and estrogen, long acting implants and injections containing synthetic progesterone (Asa, 2018) (progestins viz.,
Pet Centre, University of Veterinary and Animal Sciences, Lahore54000, Pakistan.

Corresponding Author: U.F. Durrani, Pet Centre, University of Veterinary and Animal Sciences, Lahore-54000, Pakistan.

Email: ufdurrani@uvas.edu.pk

How to cite this article: Tahir, H.A., Durrani, U.F., Mahmood, A.K., Matloob, K., Imran, M. and Hussain, R. (2022). Study on Effects of Medroxyprogesterone Acetate on Serological Parameters, Ultrasonographic and Histopathological Profile of Uterine Endometrial Morphology in Female Rabbits. Indian Journal of Animal Research. DOI: 10.18805/IJAR.BF-1439.

Submitted: 16-09-2021 Accepted: 20-12-2021 Online: 06-01-2022

Megesterol acetate and Medroxyprogesterone acetate) produce artificial luteal phase thereby inhibiting estrogen release in receptive female that leads to anestrus. Corticosteroid metabolism is complex which includes enzyme induction, protein binding, molecular intervention which generally take place in hepatic P450 system (Lansang and Hustak 2011) due to which chronic or high dose usage may cause persistence rise in liver enzymes. Similarly, due to effects on insulin resistance, use corticosteroids is commonly implicated in drug-induced diabetes mellitus (Xu et al. 2007), due to these pharmacokinetic and 
pharmacodynamic properties the present study was designed to study the effect of Medroxyprogesterone acetate on liver enzymes, blood glucose and lipid profile as well as ultrasonographic and histopathological effect on uterine endometrial morphology in female rabbits.

\section{MATERIALS AND METHODS}

Present study was conducted at Pet Centre, University of Veterinary and Animal Sciences, Lahore, Pakistan during the year 2018. The study involved 20 adult female domestic rabbits (Oryctolagus cuniculus) purchased from Local Market of Lahore, as a research project of an MPhil scholar of the Department of Pet Centre. Before commencement of the study all the rabbits were ultrasonographically examined to roll out the pregnancy using the linear probe having $3 \mathrm{MHz}$ frequency and assisted by standoff technique. Twenty nonpregnant females, fit for the study, were selected for therapeutic trial. All twenty female rabbits were equally and randomly divided into 2 groups $A$ and $B$ designated as Treatment and control group, respectively. All treatment and euthanasia procedures were opted according to protocols issued by ORIC of the institution. Furthermore, an ethical review certificate was also issued from ethical committee of university to conduct this study in the department.

\section{Therapeutic trial}

\section{Group A}

Group A was treated with single dose of Medroxyprogesterone acetate at the dose rate $10 \mathrm{mg} / \mathrm{kg}$ body weight as deep intramuscular injection in gluteal muscle.

\section{Group B}

Group B was maintained under the same management conditions as Treatment group but contraceptive injection was replaced with injection of Normal Saline.

\section{Pre and post treatment}

Pre and post treatment blood samples were collected on weekly intervals starting from day 0 till day 42 (6 week). For each sample $2 \mathrm{~mL}$ blood was collected from the jugular vein by using the $3 \mathrm{~mL}$ hypodermic syringe and needle under aseptic conditions and shifted to clot activator and serum gel separator (Polyester gel and silicon particles) containing vacutainers. After 30 minutes the blood samples were centrifuged at $4000 \mathrm{rpm}$ for 5 minutes for serum separation using centrifuge machine. Each separated serum sample was shifted and marked in a separate eppendorf tube for further processing on automated chemistry analyzer machine for following parameters.

\section{Liver function test and blood glucose}

Serum samples were placed in the chemistry analyzer machine having capacity to run 60 samples at a time each sample took 20 minutes to complete. Blood glucose and LFT (liver function test) including alanine aminotransferase $(A L T)$, aspartate aminotransferase (AST), alkaline phosphatase (ALP) and total bilirubin were measured.

\section{Lipid profile}

Lipid profile assay was performed to determine the values of total cholesterol, Triglycerides (TGs), HDL (high density lipoprotein) and LDL (low density lipoprotein). The value of LDL (low density lipoprotein) was calculated by using the formula:

$$
\mathrm{LDL}=\text { Total cholesterol }+\left[\mathrm{HDL}-\left(\frac{\mathrm{TGs}}{5}\right)\right]
$$

\section{Euthanasia protocol}

After completion of clinical study, all rabbits were deeply anaesthetized with intramuscular administration of XylazineKetamine (1:2) followed by intra-cardiac administration of $1 \mathrm{mEq} / 1 \mathrm{~mL}$ Potassium Chloride solution.

\section{Post-mortem examination}

During post-mortem gross uterine examination (Fig 1) was performed on all rabbits of treatment (Treatment) and control groups followed by uterine sample collection in $10 \%$ formalin histopathological examination.

\section{Histopathological findings}

Histopathological findings revealed congestion, engorgement of blood vessels, degeneration, hyperplasia of epithelium of uterine wall and uterine glands in Treatment group while mild proliferation of fibrous connective tissue, infiltration of inflammatory cells, mild congestion and degeneration in control group (Fig 2-5).

\section{Statistical analysis}

The data was statistically analyzed by repeated measure design using ANOVA.

\section{RESULTS AND DISCUSSION}

Following were the findings on different parameters of this study.

\section{Liver function test (LFT)}

Serological assay was conducted on weekly interval from day 0-42 (6 weeks). Statistical analysis revealed a significant increase $(P<0.05)$ in total bilirubin $(0.145 \mathrm{mg} / \mathrm{dL} \pm 0.042)$, (ALT $\mathrm{U} / \mathrm{L}$ 60.6 \pm 10.99$)$, AST (48.8 U/L \pm 8.9$)$ and ALP (107.55 U/ $L \pm 15.5)$. The value of bilirubin was mildly raised in Treatment group, in contrary to control group (Fig 6, Table 1).

According to the findings of present study, Medroxyprogesterone Acetate has the tendency to affect liver enzymes as elevations 1 to 2 weeks following the treatment were observed. Mainly there was AST, ALT elevation without changes in ALP or bilirubin. These abnormalities had short durations and returned to normal till the end of study. Severe Hepatitis, in another study, has been documented due to the use of synthetic hormones (Ruggieri, 2018). Same findings were reported by Ojokuk (2010) who stated increased liver profile values during the study.

In another study, in contrary to present study, liver adenoma leading to bilirubinemia due to synthetic progesterone has been documented (Mehmood, 2018). 


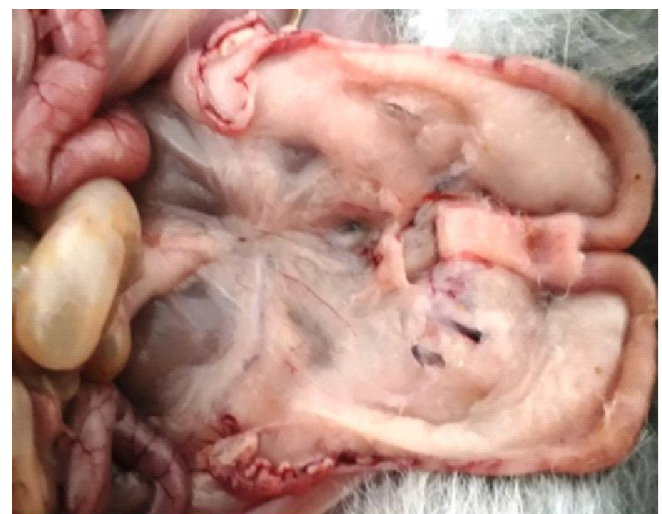

Fig 1: Uterine horns in treatment group.

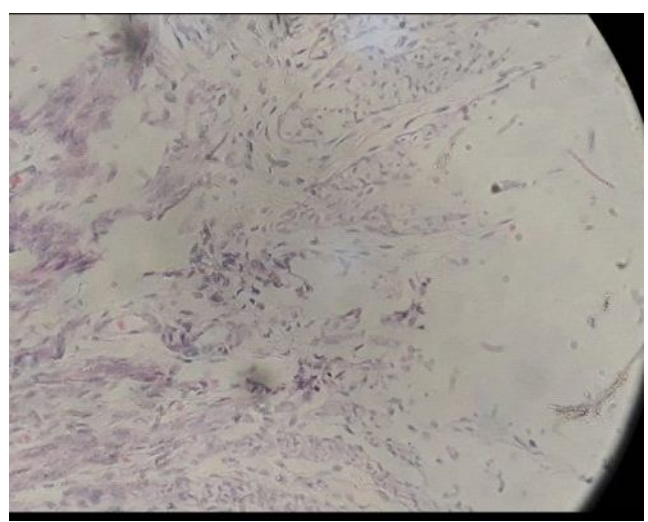

Fig 2: Infiltration of inflammatory cells.

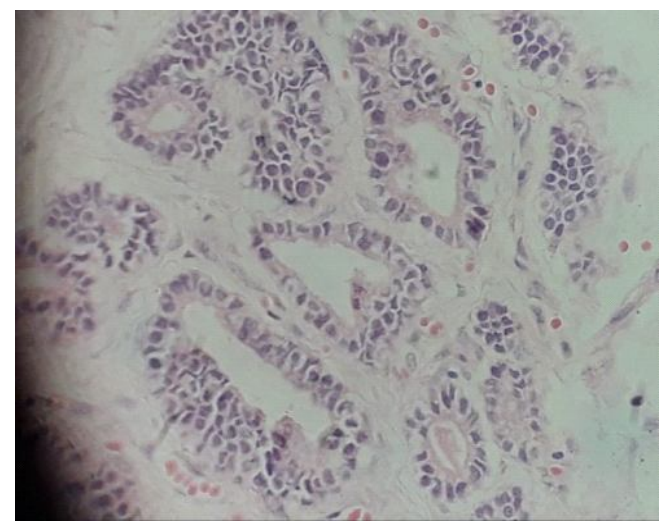

Fig 3: Hyperplasia of uterine epithelium.

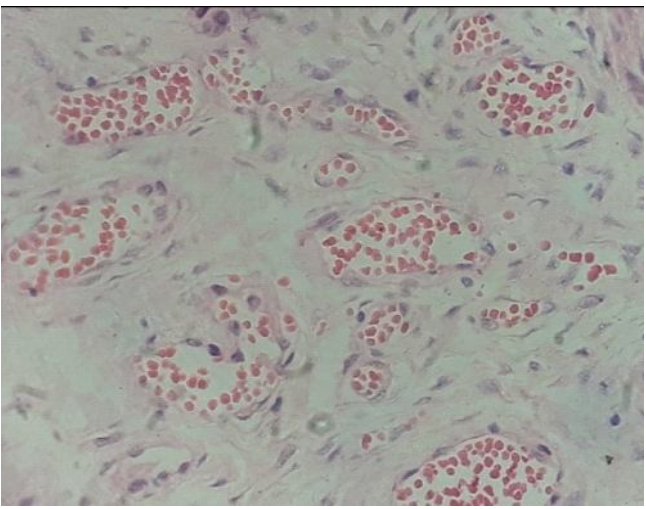

Fig 4: Engorgement of blood vessels.

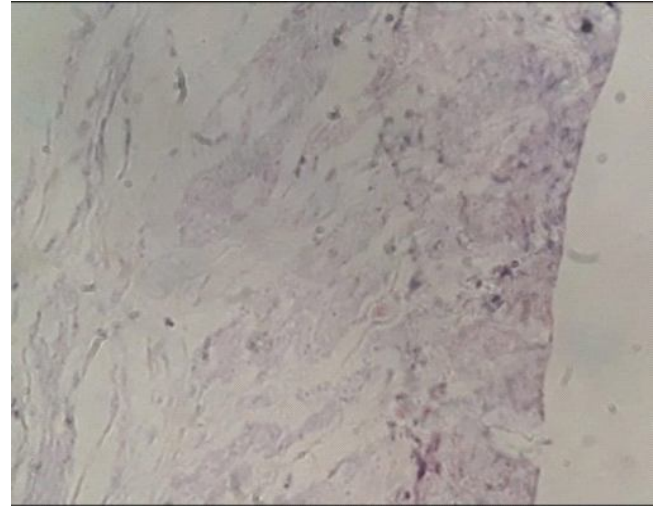

Fig 5: Fibrous connective tissue.

\section{Lipid profile}

Statistical raise $(P<0.05)$ in total serum cholesterol $(71.7$ $\mathrm{mg} / \mathrm{dL} \pm 14.47)$, HDL (64.291 mg/dL \pm 6.42$)$, LDL $(77.38 \mathrm{mg} /$ $\mathrm{dL} \pm 9.45)$, TGs (377 mg/dL \pm 75.68 ) was observed on serological assay conducted on weekly interval.

The value of LDL and cholesterol were raised in Treatment group after the Administration of Medroxyprogesterone Acetate on day 7 while no change observed in control group. Similar trend was observed on day 14 and 21.

Pronounced increases were seen in serological parameters after Medroxyprogesterone Acetate administration in Treatment group whereas drop in LDL, Triglyceride value were observed in control group. On day 35 more increase in lipid profile was observed in Treatment group as compared to control group (Fig 6, Table 1).

In present study laboratory investigations documented the raised lipid profile values after the use of synthetic progesterone in the treatment group, similar results have been documented by Dai (2004). The same findings have also been reported earlier by Tikkanen (1996) that also states that the use of synthetic progesterone has an association with chronic heart disease (CHD).

\section{Blood glucose}

Statistical analysis revealed a significant increase $(P<0.05)$ in blood glucose level $(135.71 \mathrm{mg} / \mathrm{dL} \pm 18.67)$ as compared to control group (109.11 $\mathrm{mg} / \mathrm{dL} \pm 11.71)$, although the levels were in normal ranges (Fig 6, Table 1).

Increased glucose levels in blood were documented in the present study which is in-line with the study of Adams (1990) which may also lead to diabetes mellitus (Xiang, 2006). Progesterone stimulates deposition of body fat as well which leads to obesity (Plagemann, 2006 ) which is commonly encountered clinically evident side effect of progestins in humans and other small animals.

\section{Sonographic evaluation of uterus}

No abnormality was seen in female rabbits during ultrasound examination. Ultrasonographic examination was performed in both groups on 7 days intervals from days 0-42 to evaluate in vivo uterine morphology. Ultrasonography did not reveal any significantly identifiable uterine or associated abnormality 
Table 1: Mean $\pm S E$ of different parameters during the study.

\begin{tabular}{lll}
\hline & Treatment group & Control group \\
\cline { 2 - 3 } Parameter & Mean \pm SEM & Mean \pm SEM \\
\hline Biliruben $(\mathrm{mg} / \mathrm{dL})$ & $0.145714 \pm 0.041495$ & $0.037143 \pm 0.009629$ \\
ALT $(\mathrm{U} / \mathrm{L})$ & $60.68571 \pm 10.99385$ & $45.7 \pm 12.25926$ \\
AST $(\mathrm{U} / \mathrm{L})$ & $48.8 \pm 8.868449$ & $45.91429 \pm 7.700634$ \\
ALP $(\mathrm{U} / \mathrm{L})$ & $107.5429 \pm 15.47995$ & $141.7143 \pm 25.49328$ \\
B. Glucose $(\mathrm{mg} / \mathrm{dL})$ & $135.1571 \pm 18.6694$ & $109.1143 \pm 11.70732$ \\
Cholesterol $(\mathrm{mg} / \mathrm{dL})$ & $71.7 \pm 14.4719$ & $35.51429 \pm 4.176095$ \\
HDL $(\mathrm{mg} / \mathrm{dL})$ & $64.29143 \pm 6.418714$ & $45.24286 \pm 3.140314$ \\
LDL $(\mathrm{mg} / \mathrm{dL})$ & $77.38 \pm 9.44819$ & $57.38571 \pm 6.871712$ \\
TG $(\mathrm{mg} / \mathrm{dL})$ & $377 \pm 75.67141$ & $219.4286 \pm 46.89687$ \\
\hline
\end{tabular}

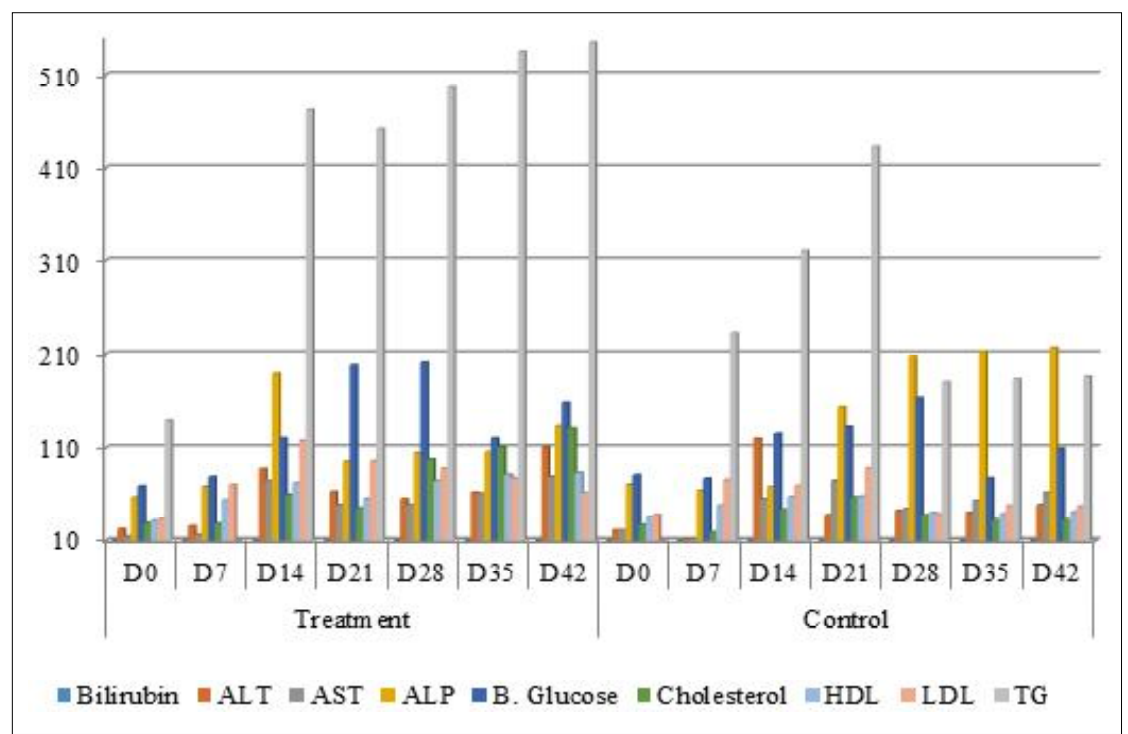

Fig 6: Trend of different parameters in treatment and control groups during study.

even in one female rabbit in which dead macerated fetuses were recovered on necropsy. Because the size of uterus is very small and placed in the deep of pelvic cavity so uterus not observe in ultrasound (Hodges, 2013).

\section{Histopathological findings}

Histopathological findings revealed congestion, engorgement of blood vessels, degeneration, hyperplasia of epithelium of uterine wall and uterine glands in Treatment group while mild proliferation of fibrous connective tissue, infiltration of inflammatory cells, mild congestion and degeneration in control group were recorded (Fig 2-5).

Necropsy examination revealed increased uterine thickness and uterine size in Treatment group but no abnormality was observed in control group, the same findings were documented by Walter (2005). Congestion, engorgement of blood vessels, degeneration, hyperplasia of epithelium of uterine wall and uterine glands in Treatment group was also evident as stated in the previously published data by De Bosschere (2003) while mild proliferation of fibrous connective tissue, infiltration of inflammatory cells, mild congestion and degeneration in control group were also observed similar to report of Aydin (2009).

\section{CONCLUSION}

Medroxyprogesterone acetate is effective contraceptive agent but it causes several serological and histo-pathological side effects on blood chemistry and uterine endometrium so it is not recommended as a safe method for contraception. The only recommended method is surgical sterilization and on the basis of findings of this study it is suggested that the present study should be extended to the other wild and domestic animal species.

\section{ACKNOWLEDGEMENT}

The study was partially supported by Pet Centre, University of Veterinary and Animal Sciences, Lahore.

\section{REFERENCES}

Adams, M.R., Kaplan, J.R., Manuck, S.B., Koritnik, D.R., Parks, J.S., Wolfe, M.S., Clarkson, T.B. (1990). Inhibition of coronary artery atherosclerosis by 17-beta estradiol in ovariectomized monkeys. Lack of an effect of added progesterone. Arteriosclerosis: An Official Journal of the American Heart Association, Inc. 10: 1051-1057. 
Asa, C.S. (2018). Contraception in Dogs and Cats. Veterinary Clinics of North America: Small Animal Practice.

Aydin, M., Cevik, A., Kandemir, F., Yuksel, M., Apaydin, A. (2009). Evaluation of hormonal change, biochemical parameters and histopathological status of uterus in rats exposed to $50-\mathrm{Hz}$ electromagnetic field. Toxicology and Industrial Health. 25: 153-158.

Dai, S., Duan, J., Lu, Y., Zhang, Y., Cheng, J., Ren, J., Zhao, X., Wu, Y., Yu, Y., Zuo, P. (2004). Phytoestrogen a-zearalanol inhibits atherogenesis and improves lipid profile in ovariectomized cholesterol-fed rabbits. Endocrine. 25(2): 121-129.

De Bosschere, H., Ducatelle, R., Tshamala, M. (2003). Uterine oestrogen and progesterone receptor expression in experimental pyometra in the bitch. Journal of Comparative Pathology. 128: 99-106.

Fuentes, G.C., Newgren, J. (2008). Physiology and clinical pathology of laboratory New Zealand White rabbits housed individually and in groups. Journal of the American Association for Laboratory Animal Science. 47: 35-38.

Hodges, R., Endo, M., La Gerche, A., Eixarch, E., DeKoninck, P., Ferferieva, V., D'hooge, J., Wallace, E.M., Deprest, J. (2013). Fetal echocardiography and pulsed-wave Doppler ultrasound in a rabbit model of intrauterine growth restriction. JoVE (Journal of Visualized Experiments). e50392.

Jiménez-Colmenero, F., Carballo, J., Cofrades, S. (2001). Healthier meat and meat products: Their role as functional foods. Meat Science. 59(1): 5-13.

Kutzler, M., Wood, A. (2006). Non-surgical methods of contraception and sterilization. Theriogenology. 66: 514-525.

Lansang, M.C., Hustak, L.K. (2011). Glucocorticoid-induced diabetes and adrenal suppression: How to detect and manage them. Cleveland Clinic Journal of Medicine. 78: 748-756.
Mehmood, A., Noor, N., Irfan, M., Sulthana, R. (2018). Physiological Jaundice in 51 Neonates. KJMS. 11: 42.

Ojokuku, S., Odesanmi, O., Magbagbeola, O. (2010). The effects of oral administration of Croton penduliflorus seed oil and Depo provera on liver and kidney functions of pregnant Dutch-white rabbits. International Journal of Biological and Chemical Sciences. 4(2). DOI: 10.4314/ijbcs.v4i2. 58146

Plagemann, A. (2006). Perinatal nutrition and hormone-dependent programming of food intake. Hormone Research in Paediatrics. 65: 83-89.

Risi, E. (2014). Control of reproduction in ferrets, rabbits and rodents. Reproduction in Domestic Animals. 49: 81-86.

Ruggieri, A., Anticoli, S. (2018). Sex-dependent outcome of Hepatitis B and $C$ viruses infections: Sinergy of sex hormones and immune responses? Frontiers in Immunology. 9: 2302.

Srivastava, N., Jain, S. (2004). Genes of Reproductive Hormones. Reproductive Biology. 3.

Tikkanen, M.J. (1996). Estrogens, progestins and lipid metabolism. Maturitas. 23: S51-S55.

Walter, L.M., Rogers, P.A., Girling, J.E. (2005). The role of progesterone in endometrial angiogenesis in pregnant and ovariectomised mice. Reproduction. 129: 765-777.

Xiang, A.H., Kawakubo, M., Kjos, S.L., Buchanan, T.A. (2006). Longacting injectable progestin contraception and risk of type 2 diabetes in Latino women with prior gestational diabetes mellitus. Diabetes Care. 29: 613-617.

Xu, J., Winkler, J., Derendorf, H. (2007). A pharmacokinetic/ pharmacodynamic approach to predict total prednisolone concentrations in human plasma. Journal of Pharmacokinetics and Pharmacodynamics. 34: 355-372. 